\title{
Study of two cohorts of workers exposed to methyl methacrylate in acrylic sheet production
}

\author{
J A Tomenson, S M Bonner, J C Edwards, M A Pemberton, T F Cummings, G M Paddle
}

ICI Epidemiology

Unit, PO Box 7, Brunner House, Winnington,

Northwich, Cheshire, CW8 4DJ, UK

J A Tomenson

S M Bonner

G M Paddle (retired)

British Steel, Health and Safety, Swinden House Moorgate, Rotherham, S60 3AR, UK

J C Edwards

ICI Acrylics, Safety,

Health and

Environment

Department,

Duckworth Street, PO Box 34, Darwen, Lancs, BB3 1QB, UK

M A Pemberton

ICI Chemicals and Polymers, Occupational Health, Wilton Site, PO Box 54, Middlesbrough, Cleveland, TS90 8JA, UK

T F Cummings

Correspondence to:

Dr J A Tomenson

john_tomenson@ici.com

Accepted 25 July 2000

\begin{abstract}
Objectives-To study mortality among 4324 workers at two United Kingdom factories, Darwen, Lancashire and Wilton, Cleveland, producing polymethyl methacrylate (PMMA) sheet. The Darwen factory is still active, but the Wilton one was closed in 1970. Also, to investigate patterns of mortality after exposure to methyl methacrylate; in particular, mortality from colon and rectal cancer.

Methods-All male employees at the Darwen factory with a record of employment in 1949-88 and all men ever employed at the Wilton factory (1949-70) were investigated. The vital status of both cohorts was ascertained on 31 December 1995. The exposure of 1526 subjects at the Darwen plant who were engaged from 1949 onwards could be characterised. The mean duration of exposure was 7.6 years at $\mathbf{1 3 . 2}$ ppm (8 hour time weighted average), although exposures in some work groups were as high as $100 \mathrm{ppm}$. It was not possible to calculate the cumulative exposure of workers first employed at the Darwen plant before 1949 or workers at the Wilton factory.
\end{abstract}

Results-In the Darwen cohort, 622 deaths were identified and a further 700 deaths in the Wilton cohort. Mortalities for the cohort were compared with national and local rates and expressed as standardised mortality ratios (SMRs). In the subcohort of Darwen workers with more than minimal exposure to MMA, reduced mortalities compared with national and local rates, were found for all causes (SMR 94), and colorectal cancer (SMR 92), but mortality from all cancers was slightly increased (SMR 104). No relations were found with cumulative exposure to MMA. In the subcohort of Wilton workers, mortality from all causes of death was significantly reduced (SMR 89), but mortality from all cancers (SMR 103) and colorectal cancer (SMR 124) were increased. The excess of colorectal cancer was confined to employees with less than 1 year of employment.

Conclusion-The study provided no clear evidence that employment at the factories or exposure to MMA had adversely affected the mortalities of workers.

(Occup Environ Med 2000;57:810-817)

Keywords: methyl methacrylate; mortality

Commercial production of polymethyl methacrylate (PMMA) sheet production began in the United Kingdom in 1936, and manufacture of other acrylic sheets incorporating methyl methacrylate (MMA) began at around the same time in the United States. Major expansion of acrylic sheet production occurred at the start of the second world war, resulting from its use in the construction of aircraft cockpit covers.

Concern about the possibility of an increased risk of colorectal cancer in workers involved in the manufacture of acrylic sheet was raised in 1984 when Rohm and Haas reported the results of a mortality investigation at their plant in Bristol, Pennsylvania. ${ }^{1}$ This finding was confirmed in an extension of the Rohm and Haas investigation conducted by Walker et $a l^{2}$ who also reported an excess of colon cancer in workers at a smaller factory at Knoxville, Tennessee. However, two other studies of workers exposed to MMA have not reported increased deaths due to colorectal cancer. $^{34}$

This report describes a cohort mortality study of workers at two ICI factories in Lancashire United Kingdom consisting of a plant which produces acrylic products at Darwen and a nearby distribution facility. The production of PMMA cast acrylic sheet, under the trade name Perspex, began at Darwen in 1940. The second world war had resulted in a huge increase in the demand for PMMA as a glazing material for aircraft. The other factory operated between 1949 and 1970 at Wilton, Cleveland. The objectives of the study were to obtain new data on the effect of human exposure to MMA, which would help to better characterise health risks, and to provide the management and workforce of the Darwen plant with information about the health risk experienced at their own plant.

\section{Materials and methods}

STUDY POPULATION AND FOLLOW UP

The design of the investigation was a retrospective cohort study of workers employed at plants producing PMMA sheet at Darwen, Lancashire and Wilton, Cleveland.

Perspex production at Darwen originally took place in a converted cotton weaving shed (Orchard Mill) and another converted weaving shed (Brittannia Mill) was added later. In the mid 1960s distribution was moved to a new factory 20 miles away at Squires Gate, Lancashire. Unfortunately, records of the workforce before 1949 were not available, but engagement and discharge registers were available from 1949 onwards and individual personnel records for workers employed on 31 December 1948 or recruited after that date. The engage- 
ment registers list in date order of recruitment all new employees at the Darwen manufacturing site or the distribution factory. The cohort included all male employees who had worked between 31 December 1948 and 31 December 1988. During the second world war, about three quarters of the workforce had been women but very few had worked in production areas since the end of the war. A total of 304 female workers were identified, but only 17 had job titles which indicated exposure to MMA and nine of these were laboratory workers. Most were clerical, cleaning, and canteen staff and it was decided not to include female workers in the study. The Darwen cohort consisted of 1887 workers at the Darwen manufacturing site and 291 workers at the distribution factory.

The Perspex factory at Wilton operated from 1949 until it closed early in 1970 . Workers in the Perspex factory were identified from engagement and discharge registers for the Plastics Division which owned the factory. The Plastics Division was itself part of a large ICI petrochemicals complex at Wilton. Because of the numerous reorganisations that have occurred within ICI since the plant closed, it was not always possible to locate individual personnel records for workers with a joining or leaving reference for the Perspex factory. Complete job histories were not routinely collected for the Wilton workers because there was limited exposure information available for the factory. No female employee in the Plastics Division had a starting or leaving reference for the Perspex factory and the Wilton cohort consisted of 2146 male workers.

The vital status of both cohorts was ascertained on 31 December 1995 from the United Kingdom National Health Service Central Register and the Department of Social Security. The underlying cause of death was coded by the Office of Population Censuses and Surveys according to either the eighth (deaths to 1978) or ninth (deaths 1979-95) revisions of the international classification of diseases (ICD-8 or ICD-9). ${ }^{56}$ Deaths occurring before the ICD-8 (1967) were recoded to the ICD revision in place at the time of death.

EXPOSURE ASSESSMENT

At the Darwen factory, personal and static monitoring data were available over some of the period, and personnel records detailing the occupational histories of cohort members were available. Consequently, it was possible to perform a comprehensive exposure assessment of workers in the Darwen cohort. Unfortunately, it was not possible to perform a similar assessment for workers in the Wilton cohort. For the Wilton workers, the duration of time employed on the Perspex plant was used as a surrogate for exposure.

At Darwen, four production units operated since 1949. The first unit, Orchard Mill, has operated since production started at the factory. Two major changes affecting the exposure of workers were considered to have occurred during the study period. The first change occurred in 1961 when the factory was expanded and ventilation was added to the syrup room areas. Previously, in the syrup rooms, MMA was activated in open vessels without extraction. In the early to mid-1970s, most of the syrup production was moved to closed vessels with provision for automated cleaning. The other three production units, Britannia Mill 1, 2, and 3, were added in 1961, 1969, and 1978. Production demands have changed since their commissioning but exposure concentrations are thought to have remained relatively constant.

Routine area monitoring data were available from 1970. Some occasional monitoring was performed before 1970 in response to incidents. Background exposure before 1970 was predicted from information about production rates, evaporation, dilution ventilation, local exhaust ventilation, and factors such as problems with "boiling up" in evacuation vessels were also incorporated. This often occurred before 1961 and was a considerable source of exposure.

A total of 589 personal monitoring results were available since 1980 . A model was developed to predict personal exposure from background exposure for 13 work groups at Orchard Mill and 14 work groups at Britannia Mill. For two work groups at Britannia Mill, casting chamber operators and syrup room operators, separate estimates were generated for the three production units. The model incorporated estimates of the time that a worker spent in different parts of the factory and the tasks performed by a worker. The model was validated with personal exposure measurements from the 1980s for 11 Orchard Mill work groups and 11 Britannia Mill work groups. The prediction model was used to estimate exposure concentrations for each of the periods during which exposure was assumed to have remained constant. Apart from a few job titles during certain periods, the estimated exposure concentrations for the different job titles at Darwen fell broadly into four groups. Job titles in the highest exposure category had mean exposure concentrations in the range of 15-25 ppm. The second group consisted of job titles with mean exposures of $2-8 \mathrm{ppm}$, and a third group included job titles which entailed low mean exposures up to $1 \mathrm{ppm}$. The fourth group consisted of distribution workers and various occupations at the cast sheet manufacturing site. This group, described as distribution and miscellaneous workers, had minimal or no exposure.

The highest exposures were experienced at Orchard Mill by syrup room operators before 1961 and shift cleaners before 1974. As noted earlier, the syrup room in Orchard Mill did not have ventilation before 1962 . It was predicted that syrup room workers had been exposed to concentrations of MMA of $45 \mathrm{ppm}$ before 1962. It was also predicted that shift cleaners in the same area would have been exposed to high concentrations of MMA when cleaning evacuation vessels. Closed evacuation vessels with provision for automated cleaning were installed in this area in 1974. The exposure of shift cleaners was estimated to be $100 \mathrm{ppm}$ before 1962 and 80 ppm between 1962 and 1974. 
Table 1 Vital status on 31 December 1995 and demographic and occupational characteristics of the Darwen and Wilton cohorts

\begin{tabular}{|c|c|c|c|}
\hline & \multicolumn{2}{|l|}{ Darwen } & \multirow[b]{2}{*}{$\begin{array}{l}\text { Wilton } \\
n(\%)\end{array}$} \\
\hline & $\begin{array}{l}\text { Britannia/Orchard } \\
n(\%)\end{array}$ & $\begin{array}{l}\text { Squires Gate } \\
n(\%)\end{array}$ & \\
\hline \multicolumn{4}{|l|}{ Year of birth: } \\
\hline$<1920$ & $493(26.1)$ & $15(5.2)$ & $526(24.5)$ \\
\hline $1920-9$ & $414(21.9)$ & $64(22.0)$ & $625(29.1)$ \\
\hline $1930-9$ & $343(18.2)$ & $78(26.8)$ & $510(23.8)$ \\
\hline$\geqslant 1940$ & $637(33.8)$ & $134(46.0)$ & $485(22.6)$ \\
\hline \multicolumn{4}{|l|}{ Year work started: } \\
\hline$<1950$ & $392(20.8)$ & $3(1.0)$ & $127(5.9)$ \\
\hline $1950-9$ & $299(15.8)$ & $8(2.7)$ & $898(41.8)$ \\
\hline $1960-9$ & $435(23.1)$ & $145(49.8)$ & $1120(52.2)$ \\
\hline $1970-9$ & $529(28.0)$ & $88(30.2)$ & $1(0.0)$ \\
\hline$\geqslant 1980$ & $232(12.3)$ & $47(16.2)$ & $0(0.0)$ \\
\hline \multicolumn{4}{|l|}{ Duration of employment (y): } \\
\hline$<5$ & $903(47.9)$ & $120(41.2)$ & $1696(79.0)$ \\
\hline $5-9$ & $290(15.4)$ & $64(22.0)$ & $286(13.3)$ \\
\hline $10-19$ & $421(22.3)$ & $59(20.3)$ & $155(7.2)$ \\
\hline$\geqslant 20$ & $273(14.5)$ & $48(16.5)$ & $9(0.4)$ \\
\hline \multicolumn{4}{|l|}{ Vital status: } \\
\hline Alive & $1222(64.8)$ & $238(81.8)$ & $1368(63.7)$ \\
\hline Dead & $575(30.5)$ & $47(16.2)$ & $700(32.6)$ \\
\hline Emigrated or joined armed forces & $32(1.7)$ & $5(1.7)$ & $59(2.7)$ \\
\hline Lost to follow up & $58(3.1)$ & $1(0.3)$ & $19(0.9)$ \\
\hline Total workers & 1887 & 291 & 2146 \\
\hline Person years of follow up & 46695.9 & 6362.7 & 66763.2 \\
\hline
\end{tabular}

For workers producing cast sheet at Darwen and recruited after 31 December 1948, lifetime cumulative exposure to MMA was calculated by summing the products of the mean concentration of exposure and duration of employment for jobs held by the employee. A more qualitative assessment of exposure effect was obtained by splitting the cast sheet production workers into two groups according to whether they had ever held a job rated as high.

The Perspex factory at Wilton was regarded as the most advanced in the world in the 1950s. Containment was considered to better than at Darwen at that time, especially in the syrup room. Closed vessels were used in the Wilton syrup room and there was roof ventilation. A major expansion in capacity occurred in 1961 at Wilton but changes to the process were relatively minor. Exposure concentrations are considered to have remained relatively constant at Wilton during the lifetime of the plant. After 1961, exposure concentrations were estimated to have been about $20 \%$ higher at Wilton than at Darwen because of the impact of modernisation work at Darwen. However, no monitoring data were available for the Wilton factory and these conclusions were largely based on anecdotal evidence. Also, full employment histories were not available for all workers and it was decided not to attempt to calculate the cumulative exposure of employees at the Wilton factory.

\section{STATISTICAL METHODS}

Mortality statistics for England and Wales were used for comparison. The occupational cohort mortality analysis program (OCMAP) ${ }^{7}$ was used to sum person-years within categories of age (5 year intervals) and calendar period (about 5 year intervals to conform with changes in the ICD), and to compute standardised mortality ratios (SMRs). For each cohort, analyses were performed for the entire cohort and the subcohort of workers who had worked for a minimum of 3 months. Also, a compari- son with local mortalities was made from information for three surrounding local districts-Darwen (Darwen manufacturing site), Teesside (Wilton), and Blackpool and Lytham St Annes (Squires Gate)-compiled for a 10 year period, 1968-78. The mortality data were compiled by the authors of an atlas of mortality. ${ }^{8}$

For the Darwen cohort, duration of employment, cumulative exposure, and latency were treated as time related variables with the values calculated for each person-year under observation. A person was allowed to contribute to more than one stratum in each analysis. Four categories of cumulative exposure to MMA were defined based on the quartiles of the distribution of cumulative exposure although these were collapsed to two categories based on the median for most analyses. Poisson regression models were fitted with adjustment for age, period, and time since first exposure. An internally standardised relative risk analysis was also performed with the distribution and miscellaneous workers group as the internal comparison group. ${ }^{9}$ For the Wilton cohort, analyses were performed only for duration of employment and latency.

\section{Results}

Table 1 shows the vital status of the Darwen and Wilton cohorts on 31 December 1995 and demographic and occupational characteristics of the cohorts. A total of 37 Darwen workers $(1.7 \%)$ had emigrated or joined the armed forces and a further 59 workers $(2.7 \%)$ were lost to follow up. At the start of follow up $56.6 \%$ were less than 35 years of age, and $89.1 \%$ were employed for at least 3 months. In the Orchard and Britannia factories 108 workers and at Squires Gate 291 workers were employed in distribution and miscellaneous jobs.

At Wilton 59 workers $(2.7 \%)$ had emigrated or joined the armed forces and a further 19 workers $(0.9 \%)$ were lost to follow up. At the start of follow up $67.8 \%$ were less than 35 years of age and $82.7 \%$ were employed for at least 3 months.

The appendix shows the exposure categories (or predicted exposure to MMA greater than $25 \mathrm{ppm}$ ) for some of the key work groups at Orchard and Britannia Mills. The appendix also shows summaries of personal monitoring results during 1980-97 for the same work groups.

The 1526 exposed sheet production workers at the Orchard and Britannia mills employed since 31 December 1948, had been exposed on average for 7.6 years at a concentration of 13.2 ppm ( 8 hours time weighted average). The mean duration of exposure of Wilton workers was 3.0 years.

Table 2 shows SMRs for the main causes of death for the Darwen and Wilton cohorts. Results for the Darwen cohort are presented separately for the Orchard/Britannia mills and the Squires Gate distribution unit. Deaths from all causes in workers from Orchard/Britannia and Squires Gate were lower than expected. Deaths due to malignant neoplasms in workers 
Table 2 Observed numbers of deaths and SMRst for selected causes of death in the Darwen and Wilton cohorts

\begin{tabular}{|c|c|c|c|c|c|c|c|c|c|}
\hline & \multicolumn{6}{|c|}{ Darwen } & & & \\
\hline & \multicolumn{3}{|c|}{ Britannia/Orchard } & \multicolumn{3}{|c|}{ Squires Gate } & \multicolumn{3}{|c|}{ Wilton } \\
\hline & $O b s$ & $S M R$ & $95 \% C I$ & Obs & $S M R$ & $95 \% C I$ & $O b s$ & $S M R$ & $95 \% C I$ \\
\hline All causes of death (001-999) & 575 & $92^{\star}$ & 85 to 100 & 47 & 96 & 70 to 127 & 700 & $89^{\star \star}$ & 82 to 96 \\
\hline All malignant neoplasms (140-208) & 166 & 99 & 84 to 115 & 18 & 124 & 73 to 196 & 223 & 103 & 90 to 117 \\
\hline Digestive system $(150-159)$ & 58 & 115 & 87 to 148 & 5 & 116 & 38 to 271 & 60 & 93 & 71 to 120 \\
\hline Oesophagus (150) & 7 & 123 & 50 to 254 & 2 & 347 & 42 to 1252 & 0 & {$\left[7.61^{\star \star}\right] \ddagger$} & - \\
\hline Stomach (151) & 21 & 133 & 82 to 203 & 0 & {$[1.16] \neq$} & - & 19 & 98 & 59 to 153 \\
\hline Colon (153) & 11 & 102 & 51 to 182 & 0 & {$[0.94] \ddagger$} & - & 21 & 151 & 93 to 230 \\
\hline Rectum (154) & 7 & 93 & 37 to 192 & 1 & 156 & 4 to 871 & 8 & 84 & 36 to 165 \\
\hline Biliary passages and liver (155-156) & 4 & 172 & 47 to 439 & 0 & {$[0.23] \ddagger$} & - & 2 & 64 & 8 to 233 \\
\hline Pancreas (157) & 7 & 99 & 40 to 203 & 1 & 156 & 4 to 868 & 9 & 97 & 45 to 185 \\
\hline Respiratory system (160-165) & 62 & 92 & 70 to 118 & 5 & 89 & 29 to 207 & 106 & $123^{\star}$ & 100 to 148 \\
\hline Larynx (161) & 1 & 62 & 2 to 345 & 0 & {$[0.15] \ddagger$} & - & 6 & $290^{\star}$ & 106 to 630 \\
\hline Bronchus, trachea, and lung (162) & 59 & 91 & 69 to 117 & 5 & 93 & 30 to 218 & 98 & 118 & 96 to 144 \\
\hline Bladder (188) & 8 & 122 & 53 to 240 & 2 & 419 & 51 to 1514 & 4 & 48 & 13 to 124 \\
\hline Brain and other CNS (191-192) & 5 & 125 & 41 to 292 & 1 & 199 & 5 to 1106 & 3 & 54 & 11 to 158 \\
\hline Lymphatic and haematopoietic tissue $(200-208)$ & 9 & 85 & 39 to 162 & 1 & 93 & 2 to 519 & 9 & 63 & 29 to 120 \\
\hline Leukaemia (204-208) & 5 & 125 & 41 to 291 & 0 & {$[0.38] \ddagger$} & - & 7 & 132 & 53 to 271 \\
\hline Cerebrovascular disease $(430-438)$ & 52 & 98 & 73 to 128 & 3 & 94 & 19 to 274 & 54 & 84 & 63 to 110 \\
\hline All heart disease $(390-398,402,404,410-429)$ & 198 & $87^{\star}$ & 75 to 100 & 15 & 79 & 44 to 130 & 276 & 94 & 83 to 106 \\
\hline Ischaemic heart disease $(410-414)$ & 176 & 87 & 75 to 101 & 15 & 86 & 48 to 142 & 251 & 96 & 85 to 109 \\
\hline Non-malignant respiratory disease $(460-519)$ & 64 & 89 & 69 to 114 & 4 & 107 & 29 to 274 & 64 & $77^{\star}$ & 59 to 99 \\
\hline Asthma (493) & 1 & 54 & 1 to 301 & 0 & {$[0.19] \ddagger$} & - & 0 & {$[2.4] \ddagger$} & - \\
\hline External causes of death (800-999) & 21 & 84 & 52 to 128 & 3 & 100 & 21 to 293 & 23 & $67^{\star}$ & 42 to 100 \\
\hline
\end{tabular}

${ }^{\star} \mathrm{p}<0.05 ;{ }^{\star \star} \mathrm{p}<0.01, \mathrm{SMR}$ significantly different from 100

†Mortalities for England and Wales.

†Expected value.

from Orchard/Britannia were close to expected, but non-significantly increased in those from Squires Gate (SMR 124). Deaths due to the cancers initially of interest-that is colon and rectal cancers-were lower than expected in workers from Orchard/Britannia (18 observed deaths versus 18.32 expected). There was one death from colorectal cancer in Squires Gate workers (1.58 expected). The increased mortality due to malignant neoplasms in workers from Squires Gate was principally due to small excesses of oesophageal cancer and bladder cancer. Mortality from causes other than malignant neoplasms was lower than expected in workers from both Orchard/Britannia (SMR 90) and Squires Gate (SMR 84). There was one asthma death in a worker from Orchard/Britannia (1.85 expected) and none at Squires Gate.

In the subcohort of 1779 Darwen workers who had experienced more than minimal exposure to MMA - that is, excluding distribution and miscellaneous workers-reduced mortalities were found for all causes (SMR 94, 519 deaths) and colorectal cancer (SMR 92, 15 deaths), but mortality from all cancers was slightly increased (SMR 104, 150 deaths).
Results for workers with more than 3 months of employment were similar and are not presented.

In the Wilton cohort, deaths from all causes were significantly reduced $(p<0.01)$ but deaths from all malignant neoplasms were slightly increased (SMR 103). In this cohort there was a non-significant excess of colon cancers (SMR 151), but deaths due to rectal cancer were slightly reduced (SMR 84). In total there were 29 deaths from colorectal cancer (SMR 123). Deaths due to cancer of the respiratory system were significantly increased $(p<0.05)$. These included a significant increase in laryngeal cancer mortality $(\mathrm{p}<0.05)$ and a nonsignificant increase in mortality from lung cancer (SMR 118). Deaths due to non-malignant respiratory disease were significantly lower than expected $(\mathrm{p}<0.05)$ and there were no deaths from asthma (2.41 expected).

Table 3 provides the relative risks from internal cohort analyses of Darwen workers hired on or after 1 January 1949. Results are presented for two cumulative dose groups. The only evidence of an association between exposure to MMA and any of the conditions of

Table 3 Relative risk of selected causes of death by cumulative exposure to MMA (Darwen workers first employed after 31 December 1948) $t$

\begin{tabular}{|c|c|c|c|c|c|c|c|c|c|}
\hline \multirow[b]{3}{*}{ Causes of death } & \multirow{2}{*}{\multicolumn{2}{|c|}{$\begin{array}{l}\text { Distribution and } \\
\text { miscellaneous } \\
\text { workers }\end{array}$}} & \multicolumn{6}{|c|}{$\begin{array}{l}\text { Cumulative exposure to } M M A \text { (Darwen cast sheet production } \\
\text { workers) (ppm-y) }\end{array}$} & \multirow{3}{*}{$\begin{array}{l}p \text { Value } \\
\text { for trend }\end{array}$} \\
\hline & & & \multicolumn{3}{|c|}{$0-32($ mean $=9.0)$} & \multicolumn{3}{|c|}{$\geqslant 33($ mean $=192.2)$} & \\
\hline & Obs & $R R$ & Obs & $R R$ & $95 \% C I$ & Obs & $R R$ & $95 \% C I$ & \\
\hline All deaths & 71 & 1.0 & 196 & 1.05 & 0.81 to 1.35 & 150 & 1.10 & 0.84 to 1.43 & 0.58 \\
\hline All malignant neoplasms & 22 & 1.0 & 47 & 0.84 & 0.52 to 1.37 & 53 & 1.28 & 0.80 to 2.04 & 0.05 \\
\hline Stomach cancer & 1 & 1.0 & 6 & 3.10 & 0.37 to 26.0 & 4 & 2.78 & 0.31 to 24.9 & 0.16 \\
\hline Colorectal cancer & 3 & 1.0 & 5 & 0.78 & 0.19 to 3.30 & 3 & 0.59 & 0.12 to 2.96 & 0.48 \\
\hline $\begin{array}{l}\text { Cancer of the bronchus, trachea, } \\
\text { and lung }\end{array}$ & 5 & 1.0 & 19 & 1.27 & 0.52 to 3.08 & 20 & 1.81 & 0.76 to 4.30 & 0.11 \\
\hline Non-malignant respiratory disease & 8 & 1.0 & 17 & 0.73 & 0.32 to 1.63 & 18 & 1.09 & 0.50 to 2.38 & 0.37 \\
\hline
\end{tabular}

${ }^{\star} \mathrm{p}$ Value for test of significance of mean cumulative exposure term in Poisson regression model.

†Relative risks computed by Poisson regression with adjustment for age, period, and time since first exposure. 
interest was a just significant association for deaths due to all malignant neoplasms.

For Darwen cohort members employed at 31 December 1948, analyses were performed for distribution and miscellaneous workers and for cast sheet production workers split into two groups according to whether or not they had ever held a job included in the highest exposure category. In the group of cast sheet production workers who were never employed in a job included in the highest exposure category, there was a small, non-significant excess of deaths from colorectal cancer (SMR 203; 95\% confidence interval ( $95 \% \mathrm{CI}) 74$ to 441 , six observed) and deaths from lung cancer (SMR $125 ; 95 \%$ CI 67 to 214,13 observed). There was no evidence of similar excesses in workers who had held jobs included in the highest exposure category, but there was a significant excess of deaths from stomach cancer (SMR $337 ; 95 \%$ CI 136 to 695 , seven observed) in workers in this group.

Analyses by duration of exposure were performed for Wilton workers. The excess of colon cancer was spread across the duration of exposure groups with the largest excess seen in the $<6$ months group. A similar pattern was found when the analysis was restricted to the period 20 years after first employment on the Perspex unit. For colorectal cancer, the relative risks over years of potential exposure to MMA $(<0.5,0.5-4.9, \geqslant 5$ years $)$ were $1.0,1.04(95 \%$ CI 0.42 to 2.58$)$, and 0.78 (95\% CI $0.27-$ 2.26 ), respectively.

The increase in mortality from lung cancer in Wilton workers was largely confined to workers who worked for less than 6 months. In this group, the SMR was significantly increased (SMR 160; 95\% CI 109 to 226, 32 observed). The SMR was only slightly increased in workers who had worked for more than 6 months (SMR 105). Similar conclusions were obtained if the analysis was restricted to the period 20 years after first exposure and in internal comparisons.

The largest excess of mortality from laryngeal cancer was found in the workers exposed for less than 6 months (SMR 586; 95\% CI 121 to 1713 , three observed). The three cases in this group were all short duration employees working for periods ranging from 20 to 60 days.

\section{Discussion}

The cohorts described in this report together with four other cohorts, provide most of the information currently available about the human health effects of MMA. The two cohorts studied here consisted of workers exposed to MMA in the production of PMMA sheet. Three other cohorts consisted of workers exposed to MMA and ethyl acrylate in the course of production of acrylic sheet. ${ }^{2}{ }^{4}$ The other group in whom mortality experience has been studied, consisted of workers who had been exposed to MMA during the manufacture of acrylic fibre. ${ }^{3}$ The Rohm and Haas investigation at the Bristol plant was conducted in response to preliminary results of inhalation tests which suggested that exposure to ethyl acrylate might cause cancer in test animals. The acrylic sheet produced by Rohm and Haas also used ethyl acrylate as an ingredient until the mid-1950s. The study by Walker et al extended the Rohm and Haas investigation at the Bristol plant to include additional workers at the Bristol plant and workers at a smaller factory at Knoxville, Tennessee. Walker et al reported an SMR for colon cancer of 150 (38 observed deaths $v 25.39$ expected) in exposed workers recruited before 1946 and with more than 10 months employment. In exposed workers recruited from 1946 onwards, there was no excess of colon cancer (seven observed deaths $v 7.05$ expected). In exposed workers, there was little evidence of a relation with cumulative exposure to ethyl acrylate or MMA, although when the analysis was restricted to the period 20 years after achieving certain concentrations of cumulative exposure, the largest excess was found in the group with highest exposure.

A similar pattern for rectal cancer was reported by Walker et al. ${ }^{2}$ No cases of rectal cancer were reported in workers recruited from 1946 onwards, but in workers employed earlier, the SMR for rectal cancer was 191 (10 observed deaths $v 5.23$ expected) for the period starting 20 years after achieving certain threshold doses. There was also no relation with cumulative exposure, although the highest SMR was found in the highest exposure group.

Walker et $a l^{2}$ concluded that "the excess of colon cancers among men who have worked with EA (ethyl acrylate) and MMA, appears to be largely restricted to those who worked extensively in the early 1940 s in jobs that entailed high exposure to the vapour phase of EA and MMA monomer and to volatile by-products of the EA/MMA polymerisation process." The fitted rate ratio for colon cancer was 2.4 in the highest dose group, 20 years since achieving the exposure cut off for this group. Walker et $a l^{2}$ noted that "essentially all men who achieved this exposure dose, did so by working in the 'boil out' phase for three or more years." However, there were excesses of colon cancer in workers who were never highly exposed-for example, workers with highest ever exposure described as minimal or less (31 observed $v 21.86$ expected). Also, the Bristol plant was situated in an area with high rates of colorectal cancer and Collins et al noted that the county in which the plant was situated, had colon rates at the 75 th percentile for the United States.

An excess of colon cancer was found in employees of the Knoxville plant 20 years after achieving certain threshold doses (SMR 152; 19 observed deaths $v 12.47$ expected). ${ }^{2}$ However, the excess was confined to the lowest exposure group and there was no excess of rectal cancers (SMR 33; one observed death $v$ 3.05 expected). Early Knoxville workers experienced the high exposures associated with the boil out phase, but there was no excess of colon cancer (one observed $v 2.27$ expected) and rectal cancers (zero observed $v 0.5$ expected) in workers who had experienced exposure equiv- 
alent to 3 years and 4 months of the boil out phase, 20 years after first achieving that dose.

In the only other previous study of acrylic sheet workers ${ }^{4}$ there was no excess of colon cancer (one observed $v 7.76$ expected) and there was no excess of colon cancer in the cohort of acrylic fibre workers (one observed $v$ 2.6 expected).

In the Darwen cohort, there was no excess of colorectal cancers in cast sheet production workers. In workers recruited after 31 December 1948, there was a deficit of both colon and rectal cancers. There were eight colorectal cancers in this group (SMR 71). There was no relation with cumulative exposure to MMA. However, there was a small excess of colorectal cancer in workers who were working at the plant on 31 December 1948 (seven observed $v$ 5.12 expected). There was insufficient information about the production process before 1949 to facilitate quantitative estimation of exposure concentrations. An analysis by job title showed that the excess was confined to production workers who never worked in the highly exposed jobs.

In workers in the Wilton cohort, there was a non-significant excess of colon cancer (SMR 151), but no excess of rectal cancer (SMR 84). The Wilton plant closed in 1969 and there were insufficient records to estimate the cumulative exposure of the workers in this cohort. However, there is evidence that exposure to MMA would have been lower than at Darwen during the early years of operation. An analysis by duration showed no trend with duration and the results were similar if restricted to the period of follow up 20 years after first employment at the plant. The largest excess of deaths from colon cancer was found in workers who had worked for less than a year at the plant during the period of follow up 20 years after first employment on the plant (eight observed $v$ 4.03 expected). When colon and rectal cancers were combined, there was little evidence of increased mortality in workers with more than 1 year of employment (SMR 108, 16 observed) and no excess in workers with more than 5 years employment (SMR 96, seven observed). The only excess was found in employees with less than 1 year of employment at the Perspex plant (SMR 148, 13 observed).

The results of routine mortality surveillance for the large complex within which this plant was situated, showed an increase in proportional mortality for colon cancer in male weekly workers (proportional mortality ratio 112) and mortality from colon cancer in men was higher in the local area than the national rates (SMR 114). Male mortality from rectal cancer was also higher in the local area than nationally (SMR 120). Overall, this finding of an increase in mortality from colon cancer in the Wilton cohort does not seem to be related to employment at the Perspex plant and would seem to reflect a high local incidence of colon cancer.

It is difficult to compare exposure concentrations of workers in the various cohorts of acrylic sheet manufacturing workers. The manufacturing processes at Darwen and Wilton did not involve the boil out phase used at the Bristol and Knoxville plants. At Darwen and Wilton, flasks were evacuated with vents outside the building. Consequently, the subcohort of workers recruited before 1946 at the Bristol plant almost certainly experienced the highest mean exposure to MMA of all the cohorts studied. However, anecdotal evidence suggests that mean exposures of workers recruited before 1949 at the Darwen factory may have approached that of early Bristol workers.

Workplace exposures decreased with time at the Bristol and Darwen plants. The reduction at the Bristol plant was more pronounced and the mean exposure concentration of Darwen workers recruited from 1949 onwards and Wilton workers was higher than that of Bristol workers recruited from 1946 onwards. The later Bristol workers were assigned to four exposure groups and the most exposed of these groups included jobs with exposures in the range of 5-24 ppm. By contrast, the mean exposure of the later Darwen workers was 13.2 ppm with several work groups having exposures assessed at concentrations of $25 \mathrm{ppm}$ and upwards.

The Rohm and Haas Knoxville plant started operation in 1940 and the boil out process was also operated here until 1946. Walker et al noted that the jobs that entailed the higher exposures, particularly the boil out process, were essentially the same as those at Bristol. The acrylic sheet workers at the Sanford plant studied by Lucas et $a l^{4}$ were followed up between 1961 and 1992. It is thought that exposure concentrations to MMA during this period would have been similar to those at the other acrylics sheet plants during that period. The exposure concentrations of the acrylic fibre workers studied by Collins et al ${ }^{\beta}$ would have been very much lower than those of workers engaged in acrylic sheet production. Average concentrations of exposure were at worst $1 \mathrm{ppm}$ which occurred during the earliest years of production.

Some evidence of an increased death rate from respiratory cancer was provided by the Knoxville cohort ${ }^{2}$ and the acrylic fibre workers cohort. ${ }^{3}$ However, mortality from respiratory cancer was close to expected in the early and later Bristol cohorts ${ }^{2}$ and there was no excess in the Sanford cohort. ${ }^{4}$ The Darwen cohort provides no evidence of such an effect, but a significant excess of mortality from respiratory cancer was found in the Wilton cohort $(p<0.05)$. Mortality from lung cancer was increased (SMR 123) and mortality due to laryngeal cancer was significantly increased $(p<0.05)$. However, both excesses were primarily restricted to short term workers $(<6$ months). In the case of lung cancer, there was a significantly increased SMR of 160 (32 observed) in workers who were employed at the plant for less than 6 months, but an SMR of 105 (66 observed) in other workers. A similar pattern was found when the analysis was restricted to the period 20 years after first employment at the plant. The excess of laryngeal cancer was also most pronounced in workers who were employed on the plant for 
less than 6 months (SMR 586). Three cases were employed for periods between 20 and 60 days. Other investigations have reported increased levels of lung cancer in short term workers ${ }^{10} 11$ and there was little evidence that the excesses of lung and laryngeal cancers in the Wilton cohort were related to employment on the plant.

Small excesses of non-malignant respiratory disease were found in the Knoxville and acrylic and fibre workers cohorts, but there was no evidence of such an effect in any of the other cohorts including the Darwen and Wilton cohorts.

Mortality due to asthma is of interest because of the ongoing debate about whether MMA is linked to occupational asthma. ${ }^{12}{ }^{13}$ However, there was only one death due to asthma in the Darwen cohort (1.85 expected) and no deaths in the Wilton cohort (2.41 expected). This finding is consistent with findings from the Bristol and Knoxville cohorts. In the early Bristol cohort, there was only one death due to asthma (3.01 expected) and there were fewer deaths due to asthma than expected in the later Bristol and Knoxville cohorts. No information on asthma mortality was provided by the other two reports. ${ }^{34}$

In the Darwen cast sheet production workers, there was a small excess of deaths due to stomach cancer (SMR 136, 19 observed). This excess was largely confined to the group of workers employed on 1 January 1949 (nine observed $v 4.93$ expected). Seven of these workers had a job title which was categorised as a high exposure job during the period 194995. When the analysis was restricted to employees who had been employed in such a job, the SMR increased to 337 (95\% CI 136 to 695). All seven employees were recruited shortly after the end of the second world war and were not exposed during the war when exposures may have been high. There was no excess of stomach cancer in the Wilton cohort and the Knoxville and early Bristol cohorts. However, an excess of stomach cancer was reported in the lower exposed, later Bristol cohort (SMR 164, 14 observed deaths). There was no excess of stomach cancer in the Sanford cohort or the acrylic fibre workers cohort. Long term animal studies of $\mathrm{MMA}^{14}$ have provided no evidence of carcinogenicity. Also, mortalities from stomach cancer were high during the study period in the Darwen area. The SMR for stomach cancer among male Darwen residents was 131 compared with national rates. This was similar to the SMR of 133 observed in the subcohort of Darwen cast sheet production workers. Stomach cancer was also increased among female Darwen residents (SMR 122). Factors such as diet ${ }^{15}$ and adverse socioeconomic circumstances in childhood ${ }^{16}$ would seem to be more likely explanations for the excess of stomach cancer found in the group of production workers employed on 31 December 1948, than exposure to MMA.

The results from the Wilton cohort are of limited value. The factory had been closed for well over 20 years when this study was started and there was limited information available to assess the exposure of workers. A feasibility study had indicated that it would be extremely difficult to obtain complete job histories for all the workers on the factory. Nevertheless, it was decided that it would be worthwhile to study the mortality experience of these workers.

The engagement and discharge registers were the key enumeration source for the Wilton cohort. It would have been a huge undertaking to identify the cohort among the individual personnel records of all workers at the Wilton petrochemicals complex. For each new employee, the engagement register lists a works number and a start number which consists of the starting year and the number of new starters in that year at the time of engagement. For most of the period of operation of the Perspex plant, the personnel department recorded an employee's start number on his discharge register entry and this would not have been possible if the engagement register was incomplete. However, some workers may have worked at the Perspex factory but had starting and leaving assignments in other Plastics Division factories. Also, the engagement and discharge registers could only be used to identify workers who were employed full time at the Perspex factory and not maintenance workers and others who may only have spent some time on the factory.

The lack of complete job history information for many members of the Wilton cohort meant that it was not possible to investigate doseresponse relations between mortality from colon and lung cancer and exposure to MMA. However, we were able to look at the mortality experience of subgroups - such as workers who started and finished in process operator jobs. These investigations and analyses by duration of exposure did not suggest a causal association.

Much better job history information was available for the Darwen cohort. A potential weakness of this part of the study, was the lack of personal monitoring data before 1980 and valid area monitoring data before 1970 . However, good historical information on the processes and working conditions was available on production rates and evaporation rates, which allowed the development of a relatively complex model of exposure. Predictions derived from the model correlated well with personal monitoring data. Conclusions derived from the analyses which incorporated predictions of work group exposures were supported by analyses based on a qualitative assessment of exposure.

In the Darwen and Wilton cohorts there were 43.33 expected deaths due to colorectal cancer (48 observed). A truer measure of the power of the study is the number of expected deaths from colorectal cancer in subgroups of workers with well characterised high exposure to MMA. In the early Darwen workers (employed on 31 December 1948) who ever held a job with high exposure, there were 2.17 expected deaths from colorectal cancer (one observed). In later Darwen workers (employed on or after 1 January 1949) with greater than median cumulative exposure, there were 5.61 
Appendix

Exposure categorisation (or predicted exposure to $M M A$ if predictions $>25 \mathrm{ppm}$ ) for some of the key work groups at Orchard and Britannia mills (and summaries of personal monitoring results during 1980-97 for the same work groups)

\begin{tabular}{|c|c|c|c|c|c|c|}
\hline & \multicolumn{3}{|c|}{ Predicted $t$} & \multicolumn{3}{|c|}{ Actual 1980-97 } \\
\hline & 1949-61 & $1962-74$ & $1975-95$ & Median & $n$ & $\begin{array}{l}\text { 25th-75th } \\
\text { Percentile }\end{array}$ \\
\hline \multicolumn{7}{|l|}{ Orchard mill: } \\
\hline Syrup room & 45 & 30 & $\mathrm{H}$ & 16.3 & 41 & $11.6-24.1$ \\
\hline Casting chamber & 30 & $\mathrm{H}$ & $\mathrm{H}$ & 13.0 & 85 & $8.5-19.1$ \\
\hline Shift cleaner & 100 & 80 & $\mathrm{H}$ & 18.5 & 6 & $11.5-24.0$ \\
\hline PEV & - & 35 & 35 & 24.2 & 37 & $12.1-37.4$ \\
\hline $\begin{array}{l}\text { Colour section } \\
\text { operator }\end{array}$ & 30 & $\mathrm{H}$ & $\mathrm{H}$ & 19.0 & 41 & $8.0-43.2$ \\
\hline $\begin{array}{l}\text { Glass section } \\
\text { operator }\end{array}$ & $\mathrm{H}$ & $M$ & $M$ & 15.3 & 10 & $9.3-26.0$ \\
\hline Trucks or ovens & $\mathrm{M}$ & $M$ & $\mathrm{M}$ & 3.3 & 15 & $2.1-5.1$ \\
\hline Inspection & $\mathrm{M}$ & $M$ & $M$ & 0.8 & 9 & $0.7-1.1$ \\
\hline Britannia mill: & \multicolumn{6}{|l|}{$1961-95$} \\
\hline Syrup room & \multicolumn{3}{|l|}{$\mathrm{H}$} & 11.6 & 39 & $9.4-19.9$ \\
\hline Casting room & \multicolumn{3}{|l|}{$\mathrm{H}$} & 12.5 & 63 & $9.2-27.5$ \\
\hline Cement making & \multicolumn{3}{|l|}{$M$} & 4.0 & 25 & $2.2-6.9$ \\
\hline Ovens & \multicolumn{3}{|l|}{$M$} & 4.8 & 8 & $3.0-18.1$ \\
\hline Inspection & \multicolumn{3}{|l|}{ M } & 5.4 & 9 & $2.3-16.3$ \\
\hline Block making & \multicolumn{3}{|l|}{ M } & 6.5 & 8 & $5.8-12.6$ \\
\hline
\end{tabular}

$\dagger \mathrm{M}=$ medium, $\mathrm{H}=$ high. health effect of initial interest. Again, there was no evidence of any effect in the Darwen cohort. The excess found in the Wilton cohort was confined to workers of even shorter duration than in the case of colorectal cancer $(<6$ months) and did not suggest an association with MMA. This was also true for the laryngeal cancers in the Wilton cohort.

We thank Ken Grimson and Ken Goodwin for their valued contribution to this work and Angela Benson for preparing the manuscript.

1 Maher KV, DeFonso LR. Interim communication on the results of a mortality study hired prior to 1946. Bristol, Pennsylvania:

2 Walker AM, Cohen AJ, Loughlin JE, et al. Mortality from cancer of the colon or rectum among workers exposed to ethyl acrylate and methyl methacrylate. Scand $\mathcal{F}$ Work Envion Health 1991;17:7-19.

3 Collins JJ, Page LC, Carporossi JC, et al. Mortality patterns among men exposed to methyl methacrylate. F Occup Med 1989;31:41-6.

4 Lucas LJ. An investigation of the mortality patterns of acrylic sheet manufacturing workers exposed to methyl methacrylate and ethyl acrylate. West Paterson, New Jersey: Cytec, 1995.

5 World Health Organization. Manual of the international classification of diseases, injuries and causes of death, 8th rev. Geneva: WHO, 1967.

expected deaths from colorectal cancer (three observed). These workers had mean cumulative exposure equivalent to almost 10 years in a $20 \mathrm{ppm}$ job. The exposure of workers at the Wilton factory could not be characterised but there were 3.01 expected deaths from colorectal cancer in workers with at least 10 years of exposure (three observed). Hence across the two cohorts there was a total of 10.79 expected colorectal cancer deaths in workers in the most highly exposed subgroups and good power to detect a doubling of risk. Only seven deaths from colorectal cancer were observed in these workers.

In conclusion, the findings of the Darwen cohort lend no support to the hypothesis that the colorectal cancers in the early Bristol workers were causally related to exposure to MMA. The excess of colorectal cancers found in short term Wilton workers ( $<1$ year) seems unlikely to have resulted from exposure to MMA. Inconsistent findings from the two cohorts also occurred in the case of lung cancer, another
6 World Health Organization. Manual of the international classification of diseases, injuries and causes of death, 9th rev. Geneva: WHO, 1977.

7 Marsh GM, Preininger M. OCMAP: a user oriented occupational cohort mortality analysis program. American Statpational cohort mortal

8 Gardner MJ, Winter PD, Barker DJP. Atlas of mortality from John Wiley, 1984

9 Preston DL, Lubin JH. EPICURE: risk regression and data analysis software. Seattle, WA: Hirosoft, 1993.

10 Lamm SH, Levine MS, Starr JA, et al. Analysis of excess lung cancer risk in short term employees. Am $\mathcal{F}$ Epidemiol 1988;127:1202-9.

11 Rossiter CE. Respiratory cancer among mineral wool workers. F Occup Med 1991;33:586.

12 Pickering CAC, Brainbridge D, Birtwistle IH, et al. Occupational asthma due to methylmethacrylate in an orthopaedic tional asthma due to methylmethacryl

13 Savonius B, Heskinen H, Tuppurainen M, et al. Erratum: occupational respiratory disease caused by acrylates. Clin Exp Allergy 1993;23:712.

14 US National Toxicology Program. Toxicology and carcinogenesis studies of methyl methacrylate (CAS no. 80-62-6) in F344/N rats and $B 6^{\circ} C 3 F_{1}$ mice (inhalation studies). Research Triangle Park, NC: NTP, 1986. (NTP TR 314, NIH 87-2570.)

15 Nomura A. Stomach cancer. In: Schottenfeld D, Fraumeni $\mathrm{JF}$, eds. Cancer epidemiology and prevention, 2nd ed. New York: Oxford University Press, 1996:707-24.

16 Smith GD, Hart C, Blane D. Adverse socioeconomic conditions in childhood and cause specific adult mortality: prospective observational study. BMF 1998;316:1631-5. selected diseases in England and Wales 1968-78. Chichester:

\section{Rejected manuscripts}

Authors whose submitted articles are rejected will be advised of the decision and one copy of the article, together with any reviewer's comments, will be returned to them. The fournal will destroy remaining copies of the article but correspondence and reviewers' comments will be kept. 